\title{
ACCIÓN COLECTIVA FEMENINA REPUBLICANA: LAS DAMAS ROJAS DE MADRID (1909-1911), UNA BREVE EXPERIENCIA POLÍTICA
}

\author{
MARTA DEL MORAL VARGAS \\ Universidad Complutense de Madrid
}

RESUMEN: Este artículo trata de analizar la aparición y el desarrollo del colectivo "Damas Rojas», vinculado al republicanismo radical y nacido en Madrid de la mano del grupo barcelonés del mismo nombre, que tanta importancia tuvo durante la Semana Trágica. Se analizan sus antecedentes, sus protagonistas, la actividad desplegada por éstas y las reacciones que motivaron. Se valora como un ejemplo de acción colectiva "parcialmente transgresor», que constituye una importante experiencia en el ejercicio de la ciudadanía por parte las mujeres, a través de la cual toman la palabra y plantean reivindicaciones propias en favor de la conquista de derechos políti$\cos y$ sociales.

Palabras Clave: Género. Cultura. Madrid. Republicanismo. Acción Colectiva Femenina. Acciones Parcialmente Transgresoras.

ABSTRACT: This article analyses the appearance and developement of the pressure group «Damas Rojas», linked with radical republicanism, which was founded in Madrid by the Barcelona group of the same name, so crucial during the "Semana Trágica». An analysis is made of the precedents, protagonists and activities carried out by the group as well as the reactions that these provoked. An evaluation is made of the group as an example of a partially trangressing collective, which provided an important experience in the exercise of citizenship for these women, and trough which they gained a voice and were able to express their vindications in favour of social and political rights.

KEY WORDS: Gender. Culture. Madrid. Republicanism. Feminine Collective Action. Partially Transgressing Actions. 
1. ORÍGENES DE LA ACCIÓN COLECTIVA FEMENINA REPUBLICANA EN MADRID: LA AGRUPACIÓN FEMINISTA REPUBLICANA Y LAS DAMAS RADICALES".

Durante los primeros años del siglo XX, asistimos en Madrid a la aparición de distintos colectivos femeninos que hacen un intento por integrar un buen número de seguidoras, provenientes especialmente de las clases populares, en el mundo de la política activa. La Agrupación Femenina Socialista no fue la única asociación de mujeres vinculada a una tendencia política, existente en Madrid en los primeros decenios del siglo ${ }^{1}$. Estrechamente ligada al Partido Republicano Radical, surge la «Agrupación femenina radical» Damas Rojas, de la que se conserva muy poca documentación ${ }^{2}$. Nos encontramos en un momento, los primeros años del siglo XX, en el que se conjugan distintos elementos que darán lugar al nacimiento y desarrollo de una intensa movilización femenina. Contamos con experiencias anteriores, que dotan de base al surgimiento de nuevos grupos tanto entre las republicanas, como veremos más abajo, como entre las socialistas; se dispone de una amplia infraestructura formal e informal que canalizará estos procesos (los partidos que auspician estas agrupaciones, espacios de reunión, redes informales de relación,...) y se aprovecha una coyuntura en la que se encuentra abierto el marco de las oportunidades políticas para las mujeres, ya que, como los hombres y a diferencia de lo que ocurría en otros países como Alemania, las mujeres españolas podían reunirse, asociarse y manifestarse, aunque no podían votar ni ser elegidas ${ }^{3}$. Además, la estructura y los dirigentes de ciertos partidos son proclives o, al menos, no dificultan, la formación de secciones femeninas en su interior.

La fecha de su creación se remonta al 25 de mayo de 1909, tras la convocatoria que, desde El País, se dirige a todas las mujeres republicanas de la capital. $\mathrm{Ni}$ en el Censo de Asociaciones, publicado por el Instituto de Reformas Sociales en

* AFSM (Agrupación Femenina Socialista Madrileña); GFSM (Grupo Femenino Socialista Madrileño); AFR (Agrupación Feminista Republicana); IRS (Instituto de Reformas Sociales); JR (Juventud Republicana).

1 En adelante las alusiones al Grupo o Agrupación Femenina Socialista de Madrid se refieren a: Del Moral Vargas, Marta: «El Grupo Femenino Socialista de Madrid (1906-1914): pioneras en la acción colectiva femenina», Cuadernos de Historia Contemporánea, 2005, vol. 27, pp. 247-269.

2 Fundamentalmente la aparecida en la prensa general republicana: El País y El Heraldo de Madrid, así como ciertas referencias de la prensa de sucesos madrileña: Los Sucesos y La Semana Ilustrada. Además, conocemos algunos datos que la relacionan con un grupo similar de Barcelona gracias a la tesina inédita de: SierRA Pellón, $\mathrm{M}^{\mathrm{a}}$ del Carmen: Lerrouxismo femenino: el papel de las «Damas» en la política del Partido Radical, tesis de licenciatura, Universitat Autònoma de Barcelona, 1984.

3 McADAM, Dough, McCARTHY, John y ZALD, Mayer N.: «Oportunidades, estructuras de movilización y procesos enmarcadores: hacia una perspectiva sintética y comparada de los movimientos sociales», en Movimientos sociales: perspectivas comparadas, Madrid, Istmo, 1999, pp. 2146 y Evans, Richard: Las feministas. Los movimientos de emancipación de la mujer en Europa, América y Australasia, 1840-1920, Madrid, Siglo XXI, 1980, pp. 187-196. 
1917, ni en el libro del Registro de Asociaciones ${ }^{4}$ se las incluye. Probablemente, la causa de la primera ausencia se deba a que el grupo contó con una vida efímera, dos o tres años a lo sumo, y su declive coincidiría con el de los republicanos radicales a partir de 1910 y la aparición de proyectos rivales, como el reformista de Melquíades Álvarez en 1912-13, cuyo nacimiento terminó por acabar en la práctica con la Conjunción ${ }^{5}$. La segunda de las ausencias resulta más inexplicable. Sin embargo, no se trataba de la primera asociación republicana integrada por mujeres de la capital que no se daba de alta en el registro.

Si repasamos las referencias de prensa, comprobamos la existencia de al menos otras tres que llevaban a cabo actividades durante estos años: la Agrupación Feminista Republicana o la Sección Femenina de la Juventud Republicana, Sociedad o Agrupación Progresiva Feminista y Damas Radicales. Como ya se ha puesto de manifiesto en algunos trabajos, los colectivos republicanos entendían la militancia política como una cuestión que traspasaba los límites del interés individual del militante varón, y se hacía extensiva a todo el núcleo familiar al que pertenecía el mismo. ${ }^{6}$ Es decir, en los innumerables actos de proselitismo político emprendidos por los republicanos, se demandaba la presencia de la esposa e hijos del militante, de la familia republicana al completo. Se entendía la unidad familiar como la célula básica de la militancia activa republicana, a través de la cual se irían inculcando los ideales progresivos a las generaciones venideras de hombres y mujeres.

Eran mujeres identificadas en absoluto con las ideas del marido o del padre, que admiran a sus mismos ídolos, leen los mismos periódicos y comentan en alta voz ante la familia, los incidentes políticos. En las fiestas que dan los republicanos, solían ir, prendiendo en su pecho, alfileres representativos o adornaban su cabeza con lacito de la bandera republicana. De veras lector que resultaban simpáticas estas familias medio aburguesadas que se llaman radicales, como pudieran llamarse otra cosa, y que, estudiadas al fondo, pudieran servir de ejemplo y modelo de compenetración y afecto ${ }^{7}$.

4 INSTITUTO DE REFORMAS SOCIALES, SECCIÓN $3^{\text {a }}$ : Estadística de asociaciones. Censo electoral de asociaciones profesionales para la renovación de la parte electiva del Instituto y de las Juntas de reformas sociales y relación de las instituciones no profesionales de ahorro, cooperación y previsión en 30 de junio de 1916, Madrid, IRS, 1917 y Gobierno Civil De Madrid, Comisaría General De SeguridAD: Registro de Asociaciones, Libros $1^{\circ}-15^{\circ}$, Archivo General de la Administración, Alcalá de Henares, [(08)030.000 36/03104-03118].

5 Álvarez JunCO, José: El Emperador del Paralelo. Lerroux y la demagogia populista, Madrid, Alianza Editorial, 1990, pp. 424-425 y SuÁREZ CORTINA, Manuel: «La quiebra del republicanismo histórico, 1898-1931», en Townson, Nigel (Ed.): El republicanismo en España (1830-1977), Madrid, Alianza, 1994, pp. 153-154; ROBLES EGEA, Antonio: «La Conjunción Republicano-Socialista, una síntesis de liberalismo y socialismo», en ForCADELL, Carlos (Ed.): «A los 125 años de la fundación del PSOE. Las primeras políticas y organizaciones socialistas», en Ayer, 54 (2), 2004, p. 116.

6 Álvarez JunCO, José: El Emperador..., op. cit., pp. 390-391.

7 Declaración referida a las mujeres de clase media que formaban parte del grupo Damas 
En este sentido, la difusión de los principios republicanos entre las mujeres se convertía en un asunto clave, ya que ostentaban la responsabilidad de educar a sus hijos. Por todo lo expuesto, no nos extraña la existencia de diversos colectivos femeninos que, aunque minoritarios, ejercerían esa labor de socialización de los valores políticos del republicanismo entre las mujeres. Es posible que la mayoría de sus integrantes, especialmente las líderes de estas agrupaciones, provinieran de las clases medias burguesas, con estrecha relación con los dirigentes del partido, e incluso, mantuvieran relaciones con el mundo del feminismo librepensador de finales del XIX y principios del XX. Sin embargo, ese núcleo se ampliaría con algunas militantes de las clases populares. Se trataría de grupos de mujeres establecidos a partir de redes informales de relación, vecindad, coincidencia familiar en los espacios de sociabilidad republicanos - casinos, círculos,...- durante la celebración de actos de diversa índole. Este germen informal de movilización que finalmente desembocaría en la creación de organizaciones formales como las citadas, encajaría con los últimos modelos propuestos por algunos teóricos de las estructuras de movilización, que mezclan ambas vías, la informal y la formal, en el nacimiento y desarrollo de los procesos de acción colectiva. ${ }^{8}$

El primero de los grupos citados, llamado indistintamente en la prensa Agrupación Feminista Republicana o Sección Femenina de la Juventud Republicana, debió nacer ligado estrechamente a la Juventud republicana, lo cual evoca un paralelismo automático con los orígenes del Grupo Femenino Socialista, por el cual, las republicanas que quisieran militar activamente en el partido, independientemente de su edad, debían hacerlo a través de una agrupación tutelada por los varones jóvenes del mismo. Es la demostración de que las mujeres eran consideradas menores de edad en el imaginario simbólico de la sociedad española de principios del siglo XX, quedando situadas en los márgenes más extremos del campo republicano militante. Ambos colectivos, en colaboración, organizaban actos públicos, fundamentalmente mítines de propaganda política. En ellos, defendían principios anticlericales y favorables a la educación de «la mujer para su propia dignificación y emancipación».?

De la Sociedad o Agrupación Progresiva Feminista, carecemos de datos, excepto de la convocatoria de alguna reunión. Es posible que estuviera integrada por

Radicales de Barcelona, efectuada por el teniente de la Guardia Civil De LARA MolinA, Modesto: Fechas de sangre: dos semanas de anarquía en España. Historia, comentarios y sucesos culminantes de la rebelión de 1909, y de la huelga general revolucionaria de 1917, Madrid, Renacimiento, 1917, p. 118, citado por CONNelly, Joan: La Semana Trágica. Estudio sobre las causas socioeconómicas del anticlericalismo en España, (1898-1912), Barcelona, Ariel, 1972.

8 Me refiero a la compatibilización de las teorías de la movilización de recursos y de los procesos políticos, representadas por John McCarthy Mayer N. Zald, Charles Tilly y Sara Evans (para estudios relacionados con el feminismo), respectivamente, citadas por: McADAM, Dough, McCARTHY, John y ZALD, Mayer N.: «Oportunidades,...», art. cit., pp. 21-46.

9 El País, 22-XII-1908. 
el mismo grupo de mujeres, a pesar del cambio en su denominación. En cualquier caso, su nombre nos recuerda a la Asociación Progresiva Femenina, fundada en Barcelona hacia 1898, por Ángeles López de Ayala y Amalia Domingo Soler, ligadas al feminismo laico librepensador que se desarrolla con una intensidad semejante en esos años en Valencia y algunas zonas de Andalucía - Huelva, Málaga, Cádiz-. ${ }^{10}$

Por otra parte, disponemos de una única reseña en la prensa republicana que habla de la existencia del colectivo Damas Radicales, hacia el 14 de mayo de 1909. En ella se da cuenta de la vinculación de este grupo madrileño con su homónimo de Barcelona. Durante el proceso por los sucesos de la Semana Trágica, según declaraciones a la policía de Barcelona de Alfredo García Magallanes, teniente retirado y presidente asesor de la asociación durante algunos días, las Damas Radicales habría surgido como una facción desgajada de Damas Rojas de Barcelona. Según este individuo, las Damas Radicales eran una asociación dedicada «al socorro de las asociadas necesitadas en casos de enfermedad y falta de trabajo», y eran disidentes de las antedichas "por haber entre estas un núcleo que no estaba conforme con la asistencia a actos civiles (entierros, inscripciones y casamientos)». Efectivamente, si comparamos los estatutos de ambas asociaciones podemos comprobar cómo Damas Rojas recoge entre sus objetivos de forma específica «propagar entre las mujeres los ideales de Libertad y de República», además del socorro a las socias necesitadas y a los correligionarios perseguidos por motivos políticos, y a sus familias. Además, se prevé la creación de comisiones para la gestión de actos civiles, de colocación y de propaganda radical femenina. Sin embargo, Damas Radicales sólo recoge entre sus fines el socorro a presos por causas políticas y sociales y la ayuda a cualquier necesitado «sin distinción de raza ni origen» y declaran «excluidos del objeto de esta asociación todos los asuntos, cuestiones y actos religiosos de cualquier índole que sean» ${ }^{11}$. Además, como detalla Joan Connelly en su investigación sobre la Semana Trágica, el grupo Damas Rojas con sede en la Casa del Pueblo, estaba integrado básicamente por obreras analfabetas de las fábricas de tejidos, mientras que las Damas Radicales, establecidas en el barrio de Gracia, en el do-

10 RAmOS, M $M^{a}$ Dolores: «Identidad de género, feminismo y movimientos sociales en España», en Historia contemporánea, 2000, (II), $\mathrm{n}^{\circ}$ 21, Universidad del País Vasco, pp. 527-528 y RAMOS, M $^{\mathrm{a}}$ Dolores: «La cultura societaria del feminismo librepensador (1895-1918)», en BUSSY GENEvoIS, Danièle: Les Espagnoles dans l'bistoire. Une sociabilité démocratique, (XIXe-XXe siècles), Presses Universitaires de Vincennes, Saint-Denis, 2002, pp. 103-124; RAMOS, $M^{\text {a }}$ Dolores: «Feminismo y Librepensamiento en España. Contra las raíces de la sociedad patriarcal», en CANTERLA, Cinta (Coord.): VII Encuentro de la Ilustración al Romanticismo, Cádiz, Universidad de Cádiz, 1994, pp. 320323; FAgOAGA, Concha: «De la libertad a la igualdad: laicistas y sufragistas», en NiELfa CRISTÓBAL, Gloria y SEGURA, Cristina (Eds.): Entre la marginación y el desarrollo: mujeres y hombres en la Historia. Homenaje a María Carmen García-Nieto, Madrid, Ediciones del Orto, 1996, pp. 171-198.

${ }^{11}$ Ver Causa contra Trinidad Alted Fornet, Emiliano Iglesias Ambrosio, Luis Zurdo de Olivares y Juana Ardiaca Mas por el delito de rebelión militar, Madrid, Sucesores de J. A. Olivares, 1911. Vol. 1, pp. 365-367 y 368-380. 
micilio de su presidenta, eran mujeres instruidas de clase media a quienes preocupaba sobre todo la educación laica, y, según declaraciones de un teniente de la Guardia Civil que las investigó, la inmensa mayoría tenía una "profesión determinada», principalmente la de maestra de escuela, disponiendo de «una pequeña biblioteca, claro es que de libros de ideas avanzadas, españoles y extranjeros» ${ }^{12}$ Además, sabemos que, desde 1906, las librepensadoras establecidas en ese barrio barcelonés, comenzaron a aproximarse a las Damas Radicales lerrouxistas, hecho que vendría a añadir una prueba más a la estrecha vinculación entre el republicanismo y el librepensamiento femenino entre las clases medias en aquellos años ${ }^{13}$.

En la documentación asociada al mismo proceso, se reproduce una carta dirigida por las Damas Radicales de Madrid a las de Barcelona, en respuesta a otra leída en un mitin de la Juventud republicana el 3 de abril de 1909, en la que les confirman que implantarán su reglamento íntegramente, salvo pequeñas variaciones $^{14}$. Firman la misiva como presidenta y secretaria de la asociación, respectivamente, Vicenta Pardo y Concha Lobo, que ocupaban los mismos cargos en la Agrupación Feminista Republicana o Sección Femenina de la Juventud Rebelde. Es decir, es posible que vuelva a tratarse del mismo colectivo de mujeres, aunque reciba nombres diferentes según los casos. De cualquier forma, se trataría del grupo femenino vinculado al Partido Republicano Radical de Lerroux en la capital.

\section{LAS DaMAS RoJas DE MADRID: ¿ENCUADRAMIENTO DE MASAS EN LA AC- CIÓN POLÍTICA FEMENINA REPUBLICANA?}

Pues bien, ese mismo mes, el 24 de mayo de 1909, el concejal radical Silvestre Abellán y Juan José Serrano Bustos, miembro de la JR, convocan a las mujeres republicanas para la creación de una nueva asociación republicana femenina en Madrid, conocida como Damas Rojas, "semejante a la que tan meritorios servicios presta en Barcelona» ${ }^{15}$. Es decir, parece que en el mismo mes estarían funcionando dos organizaciones femeninas, con claros antecedentes en la capital, y deudoras de sus homónimas catalanas y que se diferenciarían notablemente en sus objetivos, siendo una de ellas estrictamente asistencial, mientras que la otra se dedicaría preferentemente a la propaganda política y la militancia activa, cumpliendo, además, con el objetivo antes mencionado.

Sin embargo, a partir de este mes, sólo aparecerán reseñas en prensa referidas a las Damas Rojas, como si el grupo integrante de Damas Radicales (o el

12 Connelly, Joan: La Semana..., op. cit.. Las declaraciones de Modesto de Lara Molina han sido citadas por la misma autora.

13 RAMOS, M M $^{\text {a }}$ Dolores: «La cultura...», art. cit., pp. 115-116.

14 Idem, pp. 384-385 y El País, 12-V-1909.

15 El País, 24-V-1909. Sobre la creación de Damas Rojas de Barcelona, ver: La Semana Ilustrada, 12-IX-1908 y Los Sucesos, 12-VIII-1908. 
mismo bajo cualquier otra denominación), dejara o bien de existir o bien de interesar a los órganos de propaganda republicana de la capital. También podría caber la posibilidad de que un importante contingente de este grupo pasara a formar parte de Damas Rojas, quedando reducida o suprimida la actividad de Damas Radicales, hasta su marginación o desaparición. En conclusión, en 1909 triunfa la postura más radical dentro del republicanismo femenino, con la aparición de Damas Rojas, el despliegue de una considerable acción política y social, así como su colaboración desde septiembre de 1909 con las militantes de la Agrupación Femenina Socialista.

$\mathrm{Al}$ no haber podido consultar documentación directa sobre esta asociación (estatutos, registros de asociadas, actas de reuniones,...), desconocemos la importancia cuantitativa que llegó a alcanzar y el perfil de sus líderes y militantes. En noviembre de 1911, con una última referencia aparecida en El Heraldo de Madrid, dando cuenta de su actividad durante las elecciones, les perdemos la pista en la prensa, que ya no volverá a mencionarlas en años sucesivos.

Aunque no disponemos de sus estatutos, gracias a la publicación del proceso a los detenidos por los sucesos de la Semana Trágica, contamos con los de las Damas Rojas de Barcelona, que, a juzgar por los comentarios vertidos en la prensa, eran el grupo inspirador de la asociación madrileña que nos ocupa. Como ya comentamos más arriba, la asociación se dedicaba a:

propagar entre las mujeres los ideales de Libertad y de República y de auxiliarse y socorrerse mutuamente las asociadas en sus necesidades, y auxiliar y socorrer a los correligionarios que por defender estos ideales sufran cualquier clase de perjuicios, así como las familias de estos.

Además,

cada Grupo se cuidará de organizar en su seno comisiones de visita a las cárceles y a las familias de los presos, visitas a enfermos y a heridos, socorro a viudas y a huérfanos, gestión de colocaciones, propaganda radical femenina, gestión de actos civiles y todas aquellas que el Grupo crea convenientes.

La motivación política del grupo se pone de manifiesto de forma clara en las primeras líneas de su texto fundacional. No sólo se contempla el auxilio moral y económico a los correligionarios, una labor que encajaría perfectamente con el rol femenino asignado en aquellos momentos de conservar y proteger la vida en su sentido más amplio, sino que, además se declaran defensoras de los ideales republicanos. Afirman su intención de emprender una labor de propaganda política en una sociedad, la española de los primeros años de siglo XX que, en virtud de la imposición de la ideología de la domesticidad, reservaba para las mujeres el ámbito privado, el espacio doméstico y les vetaba el acceso a la tribuna pública y a los derechos políticos, incluido, por supuesto, el derecho a votar y ser elegidas como representantes de los organismos de gestión local y 
nacional. A pesar de ese orden legal y consuetudinario, las mujeres republicanas de Madrid decidieron ejercer un derecho, _ el de manifestar y difundir abiertamente sus ideas políticas - , en la medida de lo posible. Así, organizaron mítines, especialmente dedicados a combatir el clericalismo o la guerra, participaron en manifestaciones y acudieron a los colegios durante las jornadas electorales para vigilar la limpieza del procedimiento y hacer propaganda de su candidatura. Encontramos, otra vez, un paralelismo con la significación de la Agrupación Femenina Socialista: las Damas Rojas conquistaron el espacio, el discurso y las formas de actuación masculinas, como ya habían hecho tímidamente sus predecesoras de la Sección Femenina de la Juventud Republicana, destacándose como un colectivo parcialmente transgresor con el sistema de género vigente. Como ya expliqué en otro lugar $^{16}$, conquistaron las formas y los discursos pero, aunque ya surgen algunas voces aisladas en su interior, como grupo no plantearon demandas tendentes a modificar el sistema de relaciones de género vigente, la situación de las mujeres en la sociedad de entonces y sus relaciones con los hombres.

El colectivo se organizaba en torno a una junta directiva integrada por una presidenta, vicepresidenta, secretaria, vicesecretaria, contadora, tesorera y vocales, entrenándose en la práctica del sufragio activo y la discusión, dentro de la asociación, como escuela de ciudadanía política. Además, se declaraba la exclusividad femenina del mismo, aunque se debía fomentar la creación de un grupo adjunto de socios varones con fines contributivos. También se creaba la figura de los asesores, que serían dos y contarían con derecho a voz pero no a voto y el asesoramiento de tres abogados y tres médicos consultores. Todos ellos representaban la presencia de un tutelaje masculino, casi como paralelismo a nivel institucional del padre o el marido, que refuerza esa imagen de menores de edad para las mujeres de la época.

Una de sus fundadoras fue Consuelo Álvarez (Barcelona, 1866-Madrid 1957), que había pertenecido al partido Unión Republicana. Era conocida bajo el pseudónimo de Violeta, con el que firmaba sus artículos en El País ${ }^{17}$. La prensa también nos revela algunos nombres como Aurora Martínez y Josefa F. Hurtado, maestra de primera enseñanza, que ostentaron los cargos de vicepresidenta y presidenta, respectivamente, y habían pertenecido a la Agrupación Feminista Republicana, pero nada acerca de la extracción social, de las profesiones, etc. de la mayoría de las afiliadas.

Por otra parte, a través de una de las actas de la Junta general ordinaria que celebró el Grupo Femenino Socialista, sabemos que, Otilia Solera, militante socialista, había pertenecido a las Damas Rojas ${ }^{18}$. Pero no debió tratarse de un

16 Los conceptos acción parcialmente transgresora y acción globalmente transgresora han sido desarrollados en: Del Moral VARGas, Marta: «El Grupo Femenino...», art. cit.

17 FAgOAGA, Concha: La voz y el voto de las mujeres. El sufragismo en España, 1877-1931, Barcelona, Icaria, 1985, pp. 114-115.

18 GFS: Libro de actas Juntas generales, (III-1906/II-1915), FPI, Alcalá de Henares, [FPI/AASM-LVIII-2], 30-I-1910. 
caso aislado. Durante los años de vida de esta asociación, los intercambios con las militantes de la AFSM fueron constantes y de todo tipo. No sólo participaron conjuntamente en actos de propaganda política, en virtud de la unión de republicanos y socialistas en la Conjunción, sino que se produjeron fugas de socias entre uno y otro grupo. Uno de estos casos sería el de Otilia Solera, citado más arriba. De la misma forma, en el acta de la junta general celebrada el 28 de agosto de 1910, se trataba la cuestión de readmitir a la compañera Carmen Jordán que, al parecer, había dejado de pertenecer a la Agrupación "por haber tomado parte en un mitin anticlerical organizado por mujeres, sin tener permiso del Comité del Grupo y que al ser llamada la atención por el Comité, presentó la baja» ${ }^{19}$.

Otro caso destacado es el de Carmen de Burgos, Colombine, a quien, durante algunos años, se la conoció con el apodo «la Dama Roja». La adjudicación del apodo quizá ha sido interpretada en claves erróneas, asignándole unos contenidos vigentes en el universo simbólico de la guerra civil y de la posguerra que, en la España de la primera década del XX, debían ser bien distintos. Sus biógrafas coinciden en señalar que Colombine no militó expresamente en ningún partido político hasta el final de su vida, cuando, tras la proclamación de la II República, se afilia al Partido Republicano Radical Socialista ${ }^{20}$. Sin embargo, Carmen colaboró activamente con las mujeres republicanas y socialistas, al menos, entre 1910 y 1919. Es un hecho conocido que, a su regreso del primero de los viajes que realizó por Europa, inaugura en su propio domicilio «los miércoles de Colombine». Se trataba de una tertulia literaria que reunía a los escritores de mayor renombre establecidos en la capital: Blasco Ibáñez, Antonio de Hoyos y Vinent, Augusto Martínez Olmedilla, Roberto Barriobero, Pedro de Répide, Salvador Rueda, Zamacois, Cansinos-Asséns, Gómez de la Serna y José Francés. Además, acudía frecuentemente Consuelo Álvarez, Violeta, una de las fundadoras de $\mathrm{Da}$ mas Rojas. Relatos autobiográficos, como el de Cansinos-Asséns, recrean las interacciones sociales entre estos importantes personajes de la intelectualidad madrileña que tenían lugar en casa de Colombine. En las conversaciones reproducidas por el autor, se refieren a ambas con el apelativo de damas rojas, y se las presenta defendiendo apasionadamente la obtención de derechos para las mujeres (el divorcio, el acceso a una educación de mayor calidad,... $)^{21}$.

A partir de julio de 1910, Colombine inicia su militancia activa en la Agrupación Femenina Socialista, en un momento en el que el PSOE colabora con los

19 GFS: Libro de actas Juntas generales, (III-1906/II-1915), FPI, Alcalá de Henares, [FPI/AASM-LVIII-2],28-VIII-1910.

20 Castañeda, Paloma: Carmen de Burgos «Colombine», Madrid, Horas y Horas, 1994; NúÑEZ REY, Concepción: Carmen de Burgos, Colombine (1867-1932). Biografía y obra literaria, Madrid, UCM, 1992; Castillo Martin, Marcia: Carmen de Burgos (1867-1932). Colombine, Madrid, Ediciones del Orto, 2003; FrANQUESA, Lurdes: «Carmen de Burgos y Seguí», en TAVERA, Susanna (Dir.) y otras: Mujeres en la Historia de España. Enciclopedia biográfica, Barcelona, Planeta, 2000, pp. 445-448.

${ }^{21}$ CAnsinos-Asséns, Rafael: La novela de un literato, 1, Alianza, Madrid, 1982, pp. 188-191, 194-198. 
republicanos en virtud de pacto que da lugar a la Conjunción. Su militancia socialista se verá interrumpida entre mayo de 1912 y agosto de 1917, debido a una acusación formulada por dos de sus compañeras de grupo, Otilia Solera y María Ruedas. Se la acusaba de proferir palabras contrarias a las ideas socialistas en una conferencia y aunque no se pudo demostrar, este hecho debió motivar la baja voluntaria de Colombine. Pues bien, poco tiempo después, en noviembre de ese mismo año, la encontramos colaborando activamente en una iniciativa republicana para asociar a las obreras modistas. En la comisión gestora que se creará con este fin, aparece junto a Violeta, y, curiosamente, con Otilia Solera, por parte de las socialistas, así como con otros representantes del republicanismo de la capital. Estas relaciones con las redes sociales republicanas de la capital, con la vertiente femenina de la Conjunción y, especialmente, con ciertas dirigentes de Damas Rojas, como Violeta, así como el apodo referido por sus biógrafas en estos años, me llevan a sospechar que su militancia con las republicanas debió ser más activa de lo que a simple vista parece. Años después, en agosto de 1917 regresa a las filas de la AFS, grupo que no abandonará hasta diciembre de 1919.

\section{ACCIONES PARCIALMENTE TRANSGRESORAS EN LAS ACTIVIDADES DE $D A$ - MAS ROJAS (1909-1911).}

A pesar de todas las lagunas que encontramos, los diarios revelan el carácter de las actividades que organizaron y en las que tomaron parte. En la prensa republicana, como en la socialista, se pone de relieve constantemente, la presencia de las mujeres en actos políticos de todo tipo. Los textos no aclaran si a los mítines republicanos acudían mujeres ligadas al republicanismo, pero que no ejercían una militancia activa dentro de las Damas Rojas, o si, por el contrario, pertenecían, al menos en parte, a dicho colectivo. El hecho de que la asociación ya desarrollara su actividad en las fechas a las que nos referimos, nos hace pensar que entre ese importante auditorio femenino hubiera mujeres con distintos grados de compromiso con el republicanismo. Por lo que se refiere a su número, si bien los autores de las crónicas de prensa coinciden en asombrarse ante la enorme concurrencia de mujeres en este tipo de actos, imaginamos que en términos absolutos y en comparación con los varones presentes, el elemento femenino no supondría un porcentaje muy elevado. Sin embargo, aun siendo conscientes de que el republicanismo femenino activo no implicaría más de un par de centenares de trabajadoras de Madrid, resulta de enorme importancia recuperar su memoria como experiencia política pionera para las mujeres de la capital, que serviría de base y precedente de acciones posteriores.

Una de las iniciativas políticas destacadas en las que tomaron parte las republicanas durante estos años, fue la campaña a favor de la excarcelación de Macías, de acuerdo con el objetivo compartido por la mayoría de las agrupaciones 
femeninas republicanas de auxiliar a los correligionarios presos por motivos ideológicos. Su papel en esta iniciativa es destacado, de nuevo, por la prensa.

Macías del Real, perteneciente al cuerpo jurídico de la Armada, había presentado una denuncia contra el Ministro de Marina por encontrar supuestas irregularidades en la tramitación de un expediente para la concesión, a una empresa inglesa, de la construcción de tres acorazados, con un presupuesto de trescientos millones de pesetas. Los republicanos se habían opuesto, desde un primer momento, a destinar una cantidad tan elevada a la construcción de una flota que se consideraba obsoleta y exigieron que se discutiera la decisión ante el Parlamento, petición que cobró más fuerza ante los rumores de prevaricación. En medio de todo este contexto, Macías, como decimos, elevó su denuncia que le condujo a prisión por desacato a su autoridad, el Ministro. Finalmente, el Ministro de Marina repartió a los diputados un informe sobre la adjudicación de la contrata. Luis Morote, diputado republicano, en su intervención demostraba la ausencia de prevaricación en la concesión, abandonando la línea patrocinada por los republicanos. Por este motivo, renunció a su acta de diputado ${ }^{22}$.

Este hecho provocó la reacción de los republicanos y desde las páginas de $E l$ País, se inició una campaña de recogida de firmas para la excarcelación de Macías y la asunción por parte de éste del acta de diputado que Morote había dejado vacante. La movilización de la opinión pública perseguía convencer al Gobierno en este particular, ya que, con la renuncia del diputado, la minoría republicana en el Parlamento se reducía aún más. Las mujeres también manifestaron su deseo de tomar parte en la convocatoria, pero al no tener reconocidos sus derechos políticos no pudieron firmar la solicitud:

El mensaje á las Cortes.

Éxito inmenso.(...)

Las Mujeres. Muchísimas han sido las mujeres que han manifestado su deseo de poner sus nombres en el Mensaje. Por querer que sólo vaya suscrito por hombres capacitados para el ejercicio de sus derechos electorales no fue posible acceder.

Las frases mordaces, cáusticas, ingeniosísimas de algunas de dichas mujeres serían para Maura, Cierva y demás compañeros mártires, si las conocieran, una merecida y ridícula corona de espinas. $(. . .)^{23}$

Con la misma finalidad, se organizaron una serie de mítines en los que se demandaba la presencia de las mujeres, que, al producirse, despertaba los elogios de los periodistas:

Los mitins de anoche, en los que la mujer hizo, puede así decirse, acto de presencia con gallardía hasta ahora poco frecuente, en los que al entusiasmo acom-

22 Pérez Garzón, Juan Sisinio: Luis Morote: la problemática de un republicano (1862-1913), Madrid, Castalia, 1976, pp. 134-139.

${ }^{23}$ El País, 1-VI-1909. 
pañó una sensatez de hombre maduro y experimentado, son el comienzo de esta brava jornada á que el gobierno vaticanista que padecemos retó al pueblo de Madrid y de toda España por boca de su finchado ministro de la Gobernación. (... $)^{24}$

Por último, los miembros de la Juventud republicana radical, ampliando el repertorio de las formas de protesta colectiva que se venían utilizando, organizaron una recogida de tarjetas de apoyo a Macías que le entregarían personalmente en prisión. En una carta enviada a la redacción del diario republicano, se aplaude la idea de éstos jóvenes y se anima a todas las madrileñas (a todas las que no estén bajo la tutela de ningún varón) a que tomen parte en el acto. La autoría de la misiva corresponde a varias mujeres, sin que sepamos, de momento, si pertenecieron a las Damas Rojas:

\section{Sr. Director de El País:}

Muy señor nuestro y de nuestra consideración: Mucho le agradecemos las firmantes de estas humildes cuartillas publique la idea que las mismas encierran.

La iniciativa del Sr. Fernández Telo de ir á visitar al Sr. Macías del Real, el día 24 del corriente, ha sido acogida con bastante entusiasmo en Círculos y Sociedades obreras; (...)

Lo mismo al señor $\mathrm{F}$. Telo, que a las citadas entidades, que cooperan en la idea, les damos la más cordial enhorabuena por su labor, y á la vez que nos asociamos á la misma, invitamos á ir a la mujer madrileña, (claro está á excepción de las que vivan sus maridos; padres ó hermanos, de la adulación palaciega ó de la nómina de algún ministerio) á que una vez terminadas sus tareas profesionales, vayan á Prisiones ó al domicilio del señor Macías, (Santo Tomé, 6) á depositar su tarjeta, una carta ó firmar en alguna lista, todo esto en sentido de adhesión para demostrar a nuestros funestos gobernantes que la mujer española también siente simpatía hacia el profeta que sufre torturas por la patria y no por laureles, como dice el ya citado iniciador de esta simpática obra.

iManolas! iMadrileñas! A visitar el día de S. Juan al hombre digno y honrado, y demostrarle que también nosotras, sin voz ni voto, admiramos su valentía y censuramos a quienes por miedo a que hable claro en el edificio de la pastelería nacional, le tienen encerrado, (...)

María Rosario López Malla.-Teresa Vilor Fernández.- Celsa García.- María Brinchar.- Josefa Rodríguez.- Pilar Cid. ${ }^{25}$

Pero, otras informaciones publicadas más adelante, adjudicaban la autoría de la idea, no sólo a los jóvenes republicanos, sino también a las mujeres, de acuerdo con la colaboración estrecha de ambos grupos desde su nacimiento:

La manifestación de las tarjetas.

Persistimos, sin curarnos de burlas, de ingeniosidades y de dicterios, en recomen-

24 El País, 7-VI-1909.

25 El País, 22-VI-1909. 
dar la salutación al señor Macías en el día de San Juan. Jóvenes y mujeres iniciaron esa idea y trabajan por su desarrollo y buena organización. Así debía ser: la juventud es generosa, la mujer es sensible, y en este delicado recuerdo hay mucho de generosidad y no poco de sensibilidad. $(\ldots)^{26}$

La entrega de las tarjetas tuvo lugar el 24 de Junio en la prisión, a la que acudieron muchas mujeres, que, en algunos casos, tuvieron que hacer frente a las consecuencias de su movilización en sus lugares de trabajo:

Homenaje a Macías. (...) En prisiones. (...)

En los grupos heterogéneos y animosos, compuestos de obreros, empleados, agraciadas muchachas del pueblo y personas, en fin, de todas las clases, (...)

Las mujeres fueron incontables las que acudieron a felicitar al bravo acusador de Maura y sus familiares. Las cigarreras enviaron una nutrida Comisión y también otra las Damas Rojas y obreras de distintas fábricas y talleres. $(\ldots)^{27}$

Por felicitar a Macías.

En la fábrica de sobres que el Sr. Palacios tiene establecida en el núm. 16 de la calle de Cañizares, trabajan unas cincuenta mujeres entre sobreras, engomadoras y luteras.

Como hicieron otras muchas obreras de distintos talleres y fábricas, el día 24 enviaron una calurosa felicitación al Sr. Macías del Real en nombre de todas ellas.

Enteróse el jefe de la casa, que sin duda debe tener acciones en la Sociedad de Construcciones navales, será proveedor de algún ministerio, ó aspirará a serlo de la casa Vickers, y dispuso que á cada operaria se le desquitase una peseta de su jornal, porque según él, le habían multado por haber enviado sus obreras la felicitación y ellas debían pagar la multa.

Como era natural, las interesadas protestaron y no consintieron que se les hiciese tan injustificado descuento.

Cuando ayer mañana se presentaron á la hora de costumbre en la puerta de la fábrica, no se las permitió la entrada, notificándolas que estaban despedidas de la casa «por haber felicitado al Sr. Macías». (...)

Por la tarde se presentaron otra vez las despedidas en la puerta, y algo no muy grato debieron notar los dueños de la fábrica cuando dieron las oportunas órdenes para que se reanudaran las labores en los diferentes talleres.

Alguna de las obreras, con quien hablamos, nos dijo que la casa, por cualquier descuido, por pequeño que este fuera, les imponía multas casi á diario, con lo cual ven muy mermado su jornal; citándonos el caso de haber sido multadas días atrás tres de ellas, por dejar una luz unos minutos encendida, y el de imponérseles multas también por llegar unos minutos después de la hora (advirtiendo que trabajan todas á destajo.)

Damos la enhorabuena á las citadas obreras por el arreglo satisfactorio que ha tenido para ellas la cuestión surgida, y advertimos al Sr. Palacios, por si no lo sabe,

26 El País, 23-VI-1909.

27 El País, 25-VI-1909. 
que él podrá explotarlas en el trabajo cuanto pueda, pero que fuera de él son muy dueñas de pensar como les venga en ganas y que si él va muy a gusto en el machito, tal vez sus obreras estén, como estamos todos, cansadas de sufrir á la comunidad gobernante y que tienen perfectísimo derecho á manifestar sus simpatías por el caballeroso denunciador del gobierno. ${ }^{28}$

En las últimas líneas del artículo, se aprovechaba para denunciar las condiciones de trabajo de estas operarias de la fábrica de sobres y se apoya su derecho a pensar libremente y actuar en consecuencia.

Otra actividad destacada que llevaron a cabo fueron las labores de apoyo a la candidatura de la Conjunción ${ }^{29}$ durante las jornadas electorales, como las socialistas, que obtuvieron el reconocimiento de sus compañeros de partido. La prensa de sucesos de la capital recoge imágenes del reparto de candidaturas en los colegios electorales por parte de las Damas Rojas ${ }^{30}$. Las noticias en los diarios arrojan más información de su participación y de su diversa extracción social:

Celebrando el triunfo.

En el Casino Radical.

Después de las cuatro de la tarde fueron acudiendo republicanos á lo que era Centro general electoral republicano. (...)

Van llegando correligionarios y socialistas.

Se pondera el ardor de la Juventud y el entusiasmo de las compañeras del Grupo feminista, de la Agrupación obrera y de las Damas Rojas.

Dos de éstas se sabe que han sido detenidas por llevar al Casino una bandera. (...)

Las Damas Rojas en «El País».

Nos visitaron anoche en nombre de sus entusiastas compañeras, dos Damas Rojas, las señoras María de Berlana y María Martín, para felicitar á la redacción de EL PAÍS y á los candidatos triunfantes.

Agradecemos mucho la distinción conque nos han favorecido las simpáticas señoras, que con las demás, tanto han contribuido con su propaganda durante la elección á la victoria republicana.

Las elecciones generales. (...)

Distrito del Hospital. (...)

Las mujeres republicanas han tomado no pequeña parte en la contienda electoral animando á los electores á votar á los candidatos de la coalición. Dos de ellas recorrieron en coche los colegios electorales repartiendo candidaturas.

28 El País, 29-VI-1909.

29 Revisiones recientes de la historia del republicanismo: DuARTe, Ángel y Gabriel, Pere (Eds.): El republicanismo español, Ayer, 39, 2000, Madrid, Asociación de Historia Contemporánea y Marcial Pons y SuÁrez CoRTinA, Manuel: «El republicanismo español tras la crisis de fin de siglo, 1898-1914», en Cuadernos de Historia Contemporánea, nº 20, 1998, pp.165-189.

30 Los Sucesos, 14-V-1910. 
Mujeres republicanas.

Durante toda la mañana han recorrido los distritos de la Inclusa y Latina un numerosísimo grupo de mujeres del pueblo, gritando: iViva la Libertad! iAbajo los chanchulleros!, y repartiendo manifiestos y candidaturas republicanas; unos guardias quisieron disolverlas, sin conseguirlo, pues gran parte del público se puso de parte de las mujeres. ${ }^{31}$

Por el Distrito de la Inclusa ha patrullado un grupo de mujeres gritando: «iAbajo los chanchulleros!» y «iViva la República!» ${ }^{32}$

También la prensa republicana, como la socialista en el caso de las obreras que pretendían presenciar la votación, dio cuenta de un incidente, que se produjo durante los comicios, protagonizado por una republicana, cuyo marido no podía presentarse a votar, y la enviaba a ella como representante para ejercer su derecho. El hecho provocó la sorpresa y la oposición inicial de los presentes y de los encargados de la mesa. Pero ante la insistencia de la republicana, se la permitió votar "por ser muy hermosa» y por tener razón. Finalmente, uno de los presentes elogiaba la actitud de esta mujer, que había evitado que otro individuo votase por el enfermo:

Republicana entusiasta.

(...) Serían las tres de la tarde cuando una mujer del pueblo entró con resolución en el colegio instalado en la Escuela Normal.

-¿A qué viene esta señora? Le preguntaron presidente, adjuntos é interventores. Pronto iban á salir de dudas.

Aquella madrileña, sin tartamudeos, expuso:

«Señor presidente, mi esposo es elector de este distrito y tiene el voto en este colegio, y como quiera que se encuentra enfermo, conforme lo acredita este certificado facultativo, aquí estoy yo para votar por él. En este escrito, que usted puede leer, me autoriza para ello.»

-De ninguna manera, exclamaron los interventores monárquicos.

-Cómo que no. Yo voto, pésele al mismísimo conde de Romanones.

«Que mi marido es elector de esta sección, lo demuestro con su cédula, con un recibo de inquilinato y con otro acreditativo de que es un modesto industrial».

-Chico, ¿qué hacemos? Díjole un interventor monárquico á su compañero. Esta señora está decida á todo, y si no la dejamos votar armará aquí una zambra de la que vamos á salir con las manos en la cabeza.

-Tienes razón. Debemos dejar votar á esta señora por ser muy hermosa, muy resuelta y porque le asiste la razón.

El presidente con voz campanuda habló:

«Señores, ¿vota esta ciudadana por su esposo?»

Varias voces: «iQue vote, que vote!»

-«Venga pues, una candidatura republicana, señores».

31 El País, 9-V-1910.

32 ABC, 9-V-1910. 
Se le entregó á la entusiasta republicana una candidatura de la conjunción republicano-socialista la que dio al presidente, exclamando:

-iPor la República española!

Cuantas personas estaban en el colegio, electrizadas por la fe y entusiasmo de aquella señora, se levantaron y prorrumpieron en aplausos.

Los numerosos electores que estaban apostados frente al colegio, empezaron á dar vivas á las mujeres republicanas y á las madrileñas con vergüenza.

Aquella señora se marchó gozosa á su domicilio.

Al perderla de vista los electores del colegio, uno de ellos dijo:

«Si todas las mujeres fueran como ésta, pronto acabaríamos con tanto pillo.»

«Pero, que mu bien hablao. iA ver!» ${ }^{33}$

En las convocatorias a los mítines contra la guerra, se apelaba a toda la población, también a las mujeres, de nuevo en su condición de madres y esposas, conservadoras de la vida, para que mostrasen su descontento. Es decir, utilizaban aquellos argumentos que calaban en la subjetividad femenina a la hora de apelar a su movilización. La sociedad del momento esperaba de las mujeres que se dedicasen por entero a la labor de engendrar, criar y cuidar de sus hijos y, ellas mismas, en virtud de esa misión demandaban una serie de derechos para el correcto cumplimiento de sus obligaciones que, muchas veces, se convertían en el motor de acciones revolucionarias ${ }^{34}$. Es decir, paradójicamente, una protesta de raíz conservadora con el sistema de género, motivaba el despliegue de unas formas de protesta revolucionarias, - acciones parcialmente transgresoras-, al ser ejercidas por las mujeres.

También las Damas Rojas desarrollaron una intensa labor contra el reclutamiento de tropas para la guerra de Marruecos, en colaboración con los líderes de las Juventudes republicanas. Pero ésta se desarrolló solamente durante 1909-1910. En 1913, no hemos encontrado una actividad similar por su parte, hecho que probablemente se debe a la desaparición del grupo:

El mitin de anoche.

Contra la guerra.

Anoche se celebró el primero de los actos públicos, organizados por las Juventudes republicanas radicales, en contra de la guerra (...)

Habla a continuación Aurora Martínez, vicepresidenta de las Damas Rojas, y su correctísimo discurso, muy bien sentido y pensado, se encamina á describirles á

33 El País, 10-V-1910.

34 Kaplan, Temma: «Conciencia femenina y acción colectiva: el caso de Barcelona, 19101918», en Amelang, James S. y NASH, Mary (Eds.): Historia y género: las mujeres en la Europa moderna y contemporánea, Valencia, Alfons el Magnànim, 1990, pp. 267-295.; RAMos, M ${ }^{a}$ Dolores: «¿Madres de la Revolución? Mujeres en los movimientos sociales españoles (1900-1930)», en DUBY, Georges. y PERrot, Michelle: Historia de las mujeres en Occidente, Vol. 5, El siglo XX, Madrid, Taurus, 1993, pp. 523-552 y HernANDO, Almudena (Ed.): La construcción de la subjetividad femenina, Madrid, Instituto de Investigaciones Feministas, UCM, 2000. 
las señoras, los horrores de la guerra, excitándolas á que hagan obra pacifista. (Es muy felicitada y aplaudida). (... $)^{35}$

Pero la cuestión que ocupó con más intensidad a las republicanas fue el anticlericalismo. A finales de junio de 1910, ante las medidas laicas que Canalejas había puesto en marcha, una comisión de 36 señoras de la aristocracia le visitan y organizan manifestaciones y mítines, así como rezos colectivos. Además, le entregan un manifiesto, pretendidamente interclasista, en el que se declaran alarmadas ante las reformas del Gobierno y elevan este mensaje «que no es político, porque la mujer española no entiende de otra política que la de su religión» ${ }^{36}$. La reacción republicana no se hace esperar y, de este modo, lanzan una campaña desde $E l$ País contraria a la influencia del clero sobre la población y la política. Se les acusa de mantener posturas reaccionarias y perjudiciales para los intereses del pueblo, puestas de manifiesto especialmente en su actitud favorable a los recientes enfrentamientos coloniales que, desde Cuba y Filipinas hasta Marruecos, habían conducido a cientos de hombres de las clases populares a una muerte segura. Además, con su monopolio de la enseñanza, dificultan el mejoramiento de un sistema educativo obsoleto que impide a la población acceder a una formación más completa que le permita ganarse la vida sin necesidad de emigrar. Por último, se les acusa de acumular enormes riquezas que, en consecuencia, no redundan en el beneficio del total de la población. Por todos estos motivos se convoca a la ciudadanía en general y, especialmente a las mujeres a los actos anticlericales que tendrían lugar el 3 de julio: «iDespierta, pueblo! iRechazad mujeres, la representación que se arrogan cuatro aristócratas! iDemostrad que hay anticlericales en España! ${ }^{37} \mathrm{Al}$ día siguiente se publica en el mismo diario un escrito firmado por mujeres y titulado "Ahora nosotras», como respuesta a la actitud de las damas aristocráticas:

Pretenden las que pasan por damas españolas hacer ver que las mujeres de este país son gazmoñas y beatas, y siervas del Vaticano, y, por lo tanto, intentan hacer pasar a este país por un pueblo reñido con el progreso, la libertad y la cultura; las que suscriben, sin más títulos que los de obreras, y sin obedecer a más confesor y director espiritual que su propia conciencia, se proponen, a fin de desvirtuar la obra de las marquesas que han acudido a la Presidencia del Consejo de Ministros, celebrar a la mayor brevedad posible un importante acto, en el cual será nombrada una comisión que, con igual derecho que la Comisión dirigida por curas, frailes y obispos, vaya a la Presidencia del Consejo de Ministros a pedir todas las reformas que España necesita para que figure en el concierto de los pueblos libres y progresivos.

(...) Queremos demostrar que en este país ya hay mujeres que piensan y discurren, y que no tienen miedo a las excomuniones, ni al purgatorio, ni al infierno, y queremos, en fin, sumar nuestros esfuerzos a los que hagan los varones esforzados por librar a España de la intransigencia del fanatismo.

35 El País, 16-VII-1909.

36 El País, 28-VI-1910.

37 El País, 26-VI-1910. 
Así, por tanto, a nuestra labor se sumarán todas las esposas que hayan recibido aires de libertad de los esposos e hijos que sean republicanos $(\ldots)^{38}$.

Las disputas entre anticlericales y clericales surgen en todo el país, enfrentando a mujeres (Málaga, Zaragoza,...) y hombres de ambas opiniones. El debate termina centrándose en la opinión de las mujeres, ya que han sido ellas las que han encendido la chispa de la protesta y, según los republicanos, corresponde a las militantes de su partido, a las mujeres de las clases más desfavorecidas, demostrar que las clericales representan una minoría entre las españolas. Da la sensación de que los varones republicanos encuentran en esta causa la motivación adecuada para articular la participación femenina en la militancia política activa, desde su planteamiento ideológico. Podríamos considerarlo un proceso enmarcador en el sentido definido por Snow, es decir, como un «esfuerzo estratégico consciente» realizado con el fin de forjar planteamientos compartidos de concebir el mundo para legitimar y promover la acción colectiva. Una movilización que, probablemente, sin la existencia de unos significados comunes, de una visión compartida de la situación en la que se hallan inmersos, no tendría lugar, a pesar de contar con las estructuras formales e informales y con las oportunidades políticas para llevarla a cabo. El impulso final que promueve una acción colectiva de este tipo es, finalmente, un fenómeno cultural ${ }^{39}$ :

(...) Menesterosas, miserables, tomad vuestra bandera, salid como ellas al palenque; firmad exposiciones, invadid ministerios, interpelad, gritad, pedid lo vuestro. La reacción las ampara a ellas, sólo la libertad os amparará a vosotras.

Ellas os decían antes: al taller, a la fábrica, al campo: carne del trabajo, rinde tu fruto. No te mezcles en las luchas de los hombres. ¿No nos ves a nosotras?

Y vosotras debéis acudir al llamamiento por vosotras mismas, por vuestros hijos.

El clericalismo es la reacción; la reacción, la servidumbre. Con ella perdurará todo privilegio. El privilegio es la vida para vuestras adversarias, para vosotras el privilegio de la muerte.

Aniquilad el privilegio.

Un día ha de llegar en que, confundidos andrajos y sedas, cesen entre vosotras las rivalidades para defender juntas la causa de vuestra emancipación.

Y en ese día ellas confesarán cuán equivocadas estuvieron confundiendo sus faldas con las de los obispos.

Pi y Arsuaga termina este artículo vislumbrando que, por encima de las luchas políticas, una causa terminará uniendo a todas las mujeres, más allá de los conflictos de clase: la defensa de los derechos de las mujeres y de su emancipación. Encontramos un interés inicial entre los varones republicanos por convertir a sus mujeres en símbolo de sus ideas anticlericales, transmitiendo a través

38 El País, 27-VI-1910.

39 Citado por McADAm, Dough, Mccarthy, John y ZaLD, Mayer N.: «Oportunidades,...», art. cit, pp. 26-35. 
de ellas su descontento ante la protesta aristocrática, y sin embargo, ellas terminarán manifestando sus propias demandas y preocupaciones, aprovechando el foro público que se les ha abierto. De este modo, Violeta afirma:

Es preciso convencerse, mis señores arcaicos. La mujer tiene opinión y os da con ella en la cabeza cuando pierde la paciencia. La mujer necesita tomar parte en la vida nacional, y cuando el momento es llegado, se ríe de prohibiciones, sale al palenque y hace... lo que sabe... según el grado de cultura en que la habéis colocado. (.... $)^{40}$

La campaña anticlerical es enorme, implica a republicanas y socialistas e incluye muchos artículos de opinión y de convocatoria a hombres y mujeres, actos, reuniones, mítines anticlericales en Madrid y en las barriadas de la capital. $\mathrm{Al}$ no disponer de suficiente representación en los órganos políticos nacionales y municipales, la presión republicana y socialista se canaliza a través de la amenaza del orden público que constituyen el mitin y la manifestación, dotando al movimiento de una eficacia a primera vista improbable como motor del cambio social $^{41}$. La AFSM, hablando en nombre de todas las mujeres de la Conjunción, —utiliza el apelativo radicales — , publica un manifiesto de convocatoria al mitin de Barbieri y a la manifestación, y recogen firmas que se sumarían a las reunidas por distintos periódicos republicanos, liberales y socialistas. En el manifiesto se pone de relieve la escasa representatividad real con que cuenta la comisión de damas de la aristocracia que ha visitado a Canalejas:

(...) Las mujeres radicales, que indudablemente representamos a la inmensa mayoría del elemento femenino español, cual nosotras explotadas bárbara e inicuamente por quienes en un momento de desvarío afirmaron que hablaban en nombre de todas las mujeres de España, protestamos en contra de que se nos suponga defensoras de quienes viven sin trabajar.

Las señoras que tal dijeron al señor Canalejas representarán a las de su clase, a las que en ningún momento son útiles a la nación, que no quiere limosna sino trabajo; que odia los asilos de caridad y ansía, en cambio, vivir en casas higiénicas. (...) iMujeres españolas! Venid a nuestro lado a luchar porque desaparezca la explotación. iAcudid al mitin del domingo! iNo faltéis a la manifestación!

La prensa exhorta a la población:

La Conjunción republicana-socialista espera que acudan con singular entusiasmo a la manifestación que ha de celebrarse el domingo próximo 3 de julio, cuantas personas de ambos sexos anhelen proclamar enérgicamente la emancipación de la conciencia española y la supremacía del poder civil.

Ciudadanos: iahora o nunca!» (...)

40 Las referencias de Pi y Arsuaga y Violeta en: El País, 30-VI-1910.

41 TARROW, Sidney: El poder en movimiento. Los movimientos sociales, la acción colectiva y la política, Madrid, Alianza Editorial, 2004. 


\begin{abstract}
Madrileños:
Cincuenta mil ciudadanos de esta villa nos honrasteis con vuestra confianza trayéndonos al Ayuntamiento y a la Diputación provincial para representaros y representar en vuestro nombre la libertad y la República. (...)

Cincuenta mil madrileños fuisteis para llevarnos al Municipio.

Acudid a la manifestación de mañana domingo; y no acudáis solos; acudid con vuestras mujeres, con vuestras hijas, con aquellos pedazos vuestros que, si no pudieron llevar sus votos a las urnas, llevaron y llevan en sus almas el amor a la República y el culto de la libertad. ${ }^{42}$
\end{abstract}

El trayecto por el que discurrirá la manifestación, — desde el Paseo de Recoletos hasta la estatua de Castelar-, es ya un clásico en los actos públicos de protesta o celebración de los republicanos, así como el recorrido Recoletos-Casa del Pueblo, lo era para los socialistas. Aunque en este acto participarían representantes de ambas tendencias políticas, corresponde a los republicanos la iniciativa del mismo y, por este motivo, debió prevalecer un recorrido simbólicamente republicano. A través de la prensa se publica el orden estricto que los manifestantes han de seguir. Además del uso de rutas específicas, consignas y símbolos de distinto tipo, empleaban sus propios «delegados de orden», que «ostentarán un lazo rojo en el ojal de la americana», para evitar que la policía interviniese, como clara demostración de que poseían una amplia cultura política en relación con las formas de protesta y oposición al poder ${ }^{43}$. Se advierte que no se permitirán «ni emblemas ni gritos» durante el acto para evitar posibles enfrentamientos con las autoridades que podrían transformar la manifestación en un enfrentamiento abierto no deseado por los convocantes. La reciente conquista de la manifestación como pieza clave del repertorio de protesta ahora legalizada, obligaba a sus defensores a demostrar su carácter cívico y no violento en cada convocatoria. Necesitaban dejar claro que eran capaces de organizarlas sin que se produjera ni un solo episodio de desorden, ya que estas manifestaciones constituían la expresión máxima de la verdadera democracia demandada por la ciudadanía.

La manifestación termina siendo un acto multitudinario en la que las mujeres «constituyen la nota verdaderamente interesante», aventurando su número en veinte mil. Acuden representantes de las sociedades obreras de la Casa del Pueblo, como Lavanderas y Planchadoras o Modistas, señoras republicanas de todas las clases, de las que se reproducen los nombres de las de más alto rango en la escala social, pero también, —aclaran—, «son incontables las esposas e hijas de personas neutras en política y las de obreros y comerciantes que han asistido", cuyos nombres desconocen ${ }^{44}$. Actos similares tienen lugar en otras provincias como Alicante, Badajoz, Gijón, Huelva, Jaén, León,... En Barcelona, Ảngeles López

42 El manifiesto de las mujeres y la primera convocatoria en: El País, 1-VII-1910, la segunda el 2-VII-1910.

43 TARROW, Sidney: El poder en..., op. cit., p. 145.

44 El País, 4-VII-1910. 
de Ayala lidera una espectacular manifestación «femenina librepensadora» bajo la consigna: «iAbajo el clericalismo! iViva la libertad!». En las declaraciones de su presidenta, realizadas al término de la manifestación y tras entregar un escrito con más de 22.000 firmas, se deja traslucir de nuevo la idea de que la campaña anticlerical había permitido a las mujeres conquistar los canales de expresión para formular sus propias inquietudes: «La presidencia salió luego al balcón diciendo a sus compañeras que en las mujeres germina el deseo de libertad (...). Luego vitoreó a la libertad y se disolvieron con el mayor orden» ${ }^{45}$.

El acto culminante de la campaña anticlerical entre las mujeres fue, sin duda alguna, el mitin que, republicanas y socialistas, celebraron en Barbieri al que acudieron, según la prensa, unas mil mujeres. La presidencia del acto es compartida por Carmen de Burgos, Juana Taboada (una de las fundadoras del GFSM), y Herminia Martínez (perteneciente al GFSM). Además, acuden representantes de diversas entidades femeninas liberales de la capital. Las oradoras hacen hincapié en distintos asuntos que mezclan la propaganda anticlerical y la protesta de clase. Acusan a las damas aristocráticas de no representar a las mujeres de la clase trabajadora y denuncian la competencia desleal que supone el trabajo realizado por las órdenes religiosas. La presidenta de Damas Rojas y maestra de primera enseñanza, Josefa F. Hurtado, publica algunos días más tarde un artículo en defensa de la enseñanza laica ${ }^{46}$.

El debate acerca del acceso de las mujeres a una formación amplia que les permitiera desempeñar oficios hasta entonces reservados a los varones, también fue abordado por las republicanas. Una de las fundadoras de las Damas Rojas, Violeta, defendía desde las páginas de El País, la educación de las mujeres, con el fin de que conquistaran la independencia económica que les libraría de la obligatoriedad de contraer matrimonio y del desamparo ante la pérdida o la inexistencia del cónyuge. Se trata de un discurso muy habitual en los foros del momento, especialmente centrado en las muchachas de clase media que dependen del matrimonio para su subsistencia. Cuando no conseguían casarse, muchas jóvenes trataban de ganarse la vida cosiendo a domicilio y a destajo, en el mejor de los casos, mientras que otras terminaban cayendo en la prostitución como único medio de subsistencia. Este fenómeno escandalizaba a una parte de la sociedad del momento, que encontraba la solución en abrir las puertas de la enseñanza media y superior a las mujeres para que pudieran encontrar empleos dignos con los que salir adelante ${ }^{47}$ :

(...) Se la educa elevando su condición moral, haciéndola ver que el amor no es negocio, ni la unión de dos seres de distinto sexo, único medio de resolver cuestiones económicas; $(. .$.

Para amar por elección, para no aceptar la coyunda con el primer llegado, es necesario libertad económica, y esa se conquista con el trabajo. El trabajo intelectual

45 El País, 11-VII-1910. Ramos, M ${ }^{\mathrm{a}}$ Dolores: «La cultura...», art. cit., pp. 113.

46 El Heraldo de Madrid, 27-VI-1910; El País, 1-VII-1910 y 12-VIII-1910.

47 En el mismo sentido, pero desde medios socialistas: NELKEN, Margarita: La condición social de la mujer en España, Barcelona, Minerva, 1919, pp. 49-53. 
no es patrimonio de sexo alguno, el saber no es privilegio de una ni de otra mitad del género humano, y puesto que la mujer trabaja físicamente desde que el mundo es mundo, (...) iá qué obstinadamente negar lo que es bien para todos (...)?

(...) iY qué decir de las solteras madres, de las olvidadas ó desdeñadas del amor! ¿No tienen derecho, unas, a buscar en el trabajo alivio al pesar, recursos para hacer el bien; otras, a solucionar el problema del sustento corporal? ¿Y las viudas, las casadas con enfermos ó incapaces, las que no pueden, a cambio de amor, obtener protección honrosa, porque vosotros, hombres, las injuriáis, las execráis, las denostáis con saña cruel y ciega? $(. . .)^{48}$

Colombine defendía ideas similares en El Heraldo de Madrid, aunque, distanciándose del feminismo, aún no se declara partidaria de la igualdad de derechos para todos los ciudadanos, independientemente de su sexo:

(...) Las clases altas, las clases ricas, tienen la palanca poderosa de su dinero y sus costumbres para pasarlo bien dentro ó fuera del matrimonio. Hasta el convento ofrece abrigo á los últimos vástagos de familias linajudas que van á esconder en su obscuridad los últimos harapos.

En la clase media, esa desdichada clase, más culta, educada y selecta que la aristocrática, llena de necesidades y escasa de dinero, la mujer lleva un sello medioeval de esclavitud.

No se la permite trabajar, no tiene capacidad ni facilidad para lanzarse á hacer una carrera, el medio le es hostil. La que se decida á hacer algo por sí misma, á adquirir personalidad... ahí tiene la carrera de profesora. (...)

La clase trabajadora, las obreras, las sirvientes, las aldeanas, ¿qué han de hacer? Aguantarse con su miseria, quietas en su esfera, como las antiguas persas, puesto que no se les facilitan los medios de poder pasar de una clase á otra.

(...) Si educáramos á las mujeres en la ética moderna y en los adelantos de la inteligencia, para hacerlas virtuosas y libres, los pueblos serían bien pronto libres y virtuosos. No soy feminista; he reído más de una vez de los delirios igualitarios,(...); pero el problema de la educación y del trabajo femenino existen como resultado de la mala organización de nuestra sociedad y es necesario vencerlos ${ }^{49}$.

La colaboración de los hombres del partido a la hora de posibilitar la conquista de los espacios de discusión y de los medios de expresión por parte de estas mujeres en las diversas campañas emprendidas, hicieron posible que éstas pudieran formular sus propias demandas a través de los mismos, como ocurría en otros lugares del país como Valencia ${ }^{50}$.

48 El País, 3-V-1910.

49 El Heraldo de Madrid, 4-VII-1909.

50 SANFELIU, Luz: «El blasquismo en Valencia (1898-1911). Un proyecto político y la transformación de las identidades genéricas», en CERRADA, Ana I. y SEGURA, Cristina (Eds.), Las mujeres y el poder. Representaciones y prácticas de vida, Madrid, Al-Mudayna, 2000, pp. 217-224. 


\section{LA ACTITUD DE LOS VARONES DEL PARTIDO: OPINIONES CONTRADICTORIAS.}

Por otra parte, acerca de la actitud de los líderes del partido ante la movilización de las mujeres hay que decir, en primer lugar que, como es lógico, los republicanos eran hombres de su tiempo que no escapaban a la defensa de un sistema de género que les beneficiaba. Sin embargo, muchos fueron partidarios desde muy pronto de la presencia de las mujeres en los actos políticos. Su anticlericalismo les hacía comprender la necesidad de que las mujeres escapasen a la influencia de la Iglesia a través de la recepción de las ideas republicanas. Ese anticlericalismo ya había sido desarrollado por grupos de mujeres laicistas desde finales del siglo XIX. Su objetivo se centraba en conquistar una educación libre del control de la Iglesia, para construir una sociedad laica. Las demandas de libertad de conciencia de estas laicistas constituyeron un antecedente clave en el desarrollo posterior del movimiento sufragista, cuya reivindicación central será el derecho al voto. Estas ideas constituían un punto de encuentro entre las culturas políticas del librepensamiento y del republicanismo, tendiendo un puente de afinidad que facilitará la convivencia de ambas concepciones ${ }^{51}$ En un mitin de Galdós dirigido a los jóvenes, un líder republicano manifestaba lo siguiente:

\section{Julián Nogués}

(...) Me alegro de la presencia de mujeres porque hay que acostumbrarlas a que asistan á estos actos que las reivindican. En este pueblo escarnecido es justo que traigáis vuestras mujeres á los actos de expansión de ideas y progresos. Y si mañana, mujeres, os pregunta alguna comadre por qué habéis venido, en vez de dedicaros a fregar ó a poner el puchero, contestar que ellas también llevan las hijas á las procesiones y que en una nación por tantos años gobernada por mujeres y por niños, tienen derecho las mujeres y los niños á ir á todas partes. (Grandes aplausos). ${ }^{52}$

Algunas opiniones aparecidas en la prensa republicana difundían una imagen muy negativa acerca de la movilización femenina. Como muestra, las opiniones de Arturo Mori, corresponsal de El País en Barcelona, sobre una conferencia de Carme Karr acerca de la importancia de la educación de las mujeres entendida en unos términos bien distintos a los usuales — «educar en sentimientos», lo llama-:

${ }^{51}$ En relación con los grupo que defendían la conciencia libre para las mujeres, ver: FAGOAGA, Concha: «De la libertad a la igualdad: laicistas y...», art. cit., pp. 171-198; SALOMÓN CHELIZ, M ${ }^{\text {a }}$ Pilar: «Mujeres, religión y anticlericalismo en la España contemporánea: ¿para cuándo una historia desde la perspectiva de género?», en El Siglo XX: Balance y perspectivas. V Congreso de la Asociación de Historia Contemporánea, Valencia, Fundación Cañada Blanch, 2000, pp. 237-246; RAmos, $\mathbf{M}^{\mathrm{a}}$ Dolores: «La construcción de la ciudadanía...», art. cit., pp. 91-116; Miguel GonZÁLEZ, Román: «Las culturas políticas del republicanismo histórico español», en Ayer, 53 (1), 2004, pp. 231-236.

52 El País, 2-VII-1909. 
Las mujeres conspiran públicamente contra nosotros. Esa señora Carr, que ayer dio su última conferencia en el Ateneo barcelonés, sobre cultura femenina, nos ha puesto el miedo en el cuerpo. Habló de vencer á los hombres por medio de la educación, de fundar un Instituto femenino, de emprender una cruzada contra el tabaco...

(...) la señora Carr es una mujer excelente, aristocrática, amable, artista de cuerpo entero, que se ha propuesto instaurar del todo en Barcelona las teorías feministas. Por ahora, ha logrado atraer á sus conferencias un número considerable de mujeres de todas las clases sociales y despertar en ellas el deseo de emancipación.

(...) La mujer necesita que la eduquen, que la enseñen los menesteres propios de su rango femenil, que la proporcionen la base de cultura que necesita; pero enseñarla á sentir ¿por qué?

Termina solicitando una respuesta por parte de Violeta, que no se hace esperar, a pesar de que ésta no ha asistido a la conferencia objeto de los comentarios:

(...) El concepto que ha causado su alarma, querido compañero, puede ser poco alarmante en el fondo... Quizá usted, con su juvenil apasionamiento y su poquito de prevención ó prejuicio, haya dado á las palabras de la dama un alcance que no tienen... iHay que ser optimistas!

(...) Educar el sentimiento de la mujer, ¿por qué no? (...) Se la educa elevando su condición moral, haciéndola ver que el amor no es negocio, ni la unión de dos seres de distinto sexo, único medio de resolver cuestiones económicas; (...) que la madre debe aspirar á todas las sabidurías para orientar al hijo que adora por los derroteros de la existencia, (...).

Para amar por elección, para no aceptar la coyunda con el primer llegado, es necesario libertad económica, y esa se conquista con el trabajo. El trabajo intelectual no es patrimonio de sexo alguno, el saber no es privilegio de una ni de otra mitad del género humano, (...)

Creo que la señora Karr entenderá de modo semejante el feminismo y que usted, amigo mío, cuando piense formalmente, con la imparcialidad que merece la cuestión, lejos de asustarse de las «públicas conspiraciones» será un defensor hidalgo y caballero de las que no aspiran más que á contribuir sinceramente al supremo bien ${ }^{53}$.

Por otra parte, resulta curiosa la declaración de Emiliano Iglesias Ambrosio, abogado y hombre de confianza de Lerroux durante sus años de exilio, que al ser preguntado sobre la asociación Damas Rojas de Barcelona, dijo que «sabe que existen unas cuantas mujeres que se han constituido en asociación de Damas Rojas, que no tienen participación alguna en el partido y que tal asociación tampoco ha encontrado calor nunca, al menos en los intelectuales del partido, por estimarla un tanto ridícula.» ${ }^{54}$ Pero, como afirma Joan Connelly, la agrupación era muy útil a Lerroux en su propaganda, ya que le permitía proclamar que el Partido Radical no sólo había conquistado a los obreros de Cata-

53 El País, 24-IV-1910 y 3-V-1910.

${ }^{54}$ Causa contra Trinidad Alted Fornet, Emiliano Iglesias Ambrosio,..., op. cit., pp. 31-38. 
luña, sino también a sus mujeres e hijos. Para los dirigentes del partido, las Damas Rojas llevaban a cabo una labor muy importante y, a pesar de ser semianalfabetas y de no votar, constituían un grupo militante preparado para realizar todo tipo de actos, desde protestas a propaganda electoral, como vimos. ${ }^{55}$ ¿Acaso Iglesias ignoraba todo esto? Tal vez esas declaraciones formaban parte de sus intentos para exculparse de posibles condenas como instigador de los sucesos de la Semana Trágica ${ }^{56}$.

\section{CONClusiones}

En definitiva, también las mujeres republicanas expresaron sus preocupaciones políticas participando en actos de protesta de diversa índole, y creando su propia asociación. Las escasas noticias que, acerca de ésta, han llegado hasta nosotros nos impiden valorar la importancia cuantitativa de esa movilización así como el perfil sociológico de sus dirigentes y militantes.

El grupo surge en un momento en el que Madrid asiste a la creación de diversas asociaciones femeninas, vinculadas a partidos políticos, sindicatos,... como el GFSM o diversas sociedades de oficio con sede en la Casa del Pueblo. Damas Rojas, sin embargo, cuenta con varios antecedentes dignos de tener en consideración que revelan una cierta práctica política por parte de las mujeres republicanas de la capital, como lo demuestra la existencia de la Agrupación Feminista Republicana, Agrupación Progresiva Feminista o Damas Radicales.

Si atendemos a su probable vinculación con las Damas Rojas de Barcelona, nacieron con una doble vocación de militancia y proselitismo político republicano que compaginarían con labores asistenciales más adecuadas al rol esperado de las mujeres de la época. Las normas de funcionamiento del grupo lo convirtieron en una escuela de ciudadanía política para aquellas que formaron parte de él. Entre las acciones parcialmente transgresoras que protagonizaron, cabe destacar las campañas electorales de propaganda y control de la «limpieza» del proceso, en colaboración con las mujeres del GFSM, y especialmente, sus campañas anticlericales, sin olvidar su labor asistencial, como la emprendida a favor de la excarcelación de Macías.

En cualquier caso, la constatación de su existencia y de su actividad en la capital viene a sumarse a las acciones de las socialistas y de las católicas, dibujando un panorama muy interesante de la acción colectiva femenina en Madrid en las primeras décadas del siglo XX.

55 Lerroux, 15 de julio de 1910, Diario de las Cortes, III, p. 648, citado por ConNELLY, Joan: La Semana..., op. cit., pp. 159-161.

56 Álvarez Junco, José: El Emperador..., op. cit.,; Connelly, Joan: La Semana..., op. cit. 